\title{
Photodynamic Therapy of Malignant Brain Tumours
}

\author{
Paul J. Muller and Brian C. Wilson
}

\begin{abstract}
Fifty patients with malignant supratentorial tumours were treated with intra-operative photodynamic therapy (PDT); in 33 cases the tumour was recurrent. In 45 patients the tumour was a cerebral glioma and in 5 cases a solitary cerebral metastasis. All patients received a porphyrin photosensitizer 18-24 hours pre-operatively. Photoillumination was carried out at $630 \mathrm{~nm}$ to a tumour cavity created by radical tumour resection and/or tumour cyst drainage. The light energy density ranged from 8 to $175 \mathrm{~J} / \mathrm{cm}^{2}$. In 8 patients additional interstitial light was administered. The operative mortality was $4 \%$. Follow up has ranged from 1 to 30 months. The median survival for the 45 primary malignant tumours was 8.6 months with a 1 and 2 year actuarial survival rate of $32 \%$ and $18 \%$, respectively. In 12 patients a complete or near complete CT scan response was identified post PDT. These patients tended to have a tumour geometry (eg. cystic) that allowed complete or near complete light distribution to the tumour. The median survival for this group was 17.1 months with a 1 and 2 year actuarial survival of $62 \%$ and $38 \%$, respectively. In the 33 cases who did not have a complete response the median survival was 6.5 months with a 1 and 2 year actuarial survival of $22 \%$ and $11 \%$, respectively. Photodynamic therapy of malignant brain tumours can be carried out with aeceptable risk. Good responses appear to be related to adequate light delivery to the tumour.
\end{abstract}

RÉSUMÉ: Thérapie photodynamique des tumeurs malignes du cerveau Cinquante patients atteints de tumeurs malignes sus-tentorielles ont été traités par thérapie photodynamique (TPD) peropératoire; dans 33 cas, il s'agissait d'une récidive. Chez 45 patients, la tunteur était un gliome cérébral et chez 5 cas, une métastase cérébrale unique. Tous les patients ont reçu une porphyrine photosensibilisatrice 18 a 24 heures avant l'opération. On a procédé à la photóillumination à $630 \mathrm{~nm}$ au niveau d'une cavité tumorale créée par résection radicale de la tumeur et/ou par drainage d'une tumeur kystique. La densité de l'énergie lumineuse variait de 8 à $175 \mathrm{~J} / \mathrm{cm}^{2}$. Chez 8 patients on a administré de la lumière interstitielle additionnelle. La mortalité opératoire a été de 4\%. Le suivi de ces patients varie de 1 à 30 mois. La' survie médiane pour les 45 tumeurs malignes primitives était de 8.6 mois avec un taux de survie actuariel à 1 et 2 ans de $32 \%$ et $18 \%$ respectivement. Chez 12 patients, une réponse complète ou presque complète a été identifée au CT scan post PDT. Ces patients avaient en général une tumeur dont la géométrie (ex. kystique) permettait une distribution complète ou presque complète de la lunière à la tumeur. La survie médiane de ce groupe était de 17.1 mois avec un taux de survie actuariel à 1 et 2 ans de $62 \%$ et de $38 \%$ respectivement. Chez les 33 cas qui n'ont pas eu une réponse complète, la survie médiane était de 6.5 mois avec un taux de survie actuariel à 1 et 2 ans de $22 \%$ et $11 \%$ respectivement. La thérapie photodynamique des tumeurs malignes du cerveau peut être effectuée avec un niveau de risque acceptable. Les bonnes réponses semblent être liées à une distribution adéquate de la lumière à la tumeur.

Can. J. Neurol. Sci. 1990; 17: 193-198

In spite of the advances in surgery, radiation therapy and chemotherapy, the prognosis for primary malignant brain tumours remains very poor. ${ }^{1}$ These tumours result in morbidity and mortality as the consequence of their local effects on the brain; therefore, improved local control would be expected to result in prolongation of survival. Photodynamic therapy (PDT) is a local treatment which consists of the exposure of neoplastic tissue to visible light of an appropriate wavelength in order to activate a photosensitizer administered prior to the light applicalion.

A photosensitizer should ideally have no systemic toxicity. be taken up and retained by malignant tissue only, have absorp- tion of wave lengths normally transmitted by the tissue and be efficient in destroying malignant tissue. Hematoporphyrin derivative (HPD), an acidification product of hematoporphyrin (HP), ${ }^{2}$ and, dihematoporphyrin ether (DHE), a more purified form of HPD, have been the most widely used photosensitizers; ${ }^{3}$ and, have been extensively reviewed. ${ }^{4}$

The semi-selective uptake of porphyrin sensitizers in experimental and human brain tumours has been shown, $5,6,7$ and, the tumour cell cytotoxicity of PDT in a number of experimental murine brain tumour models has been demonstrated. $8,9,10$ Human brain tumour explants have also been shown in vitro to be susceptible to PDT.11

Fron the Division of Neurosurgery. Department of Surgery, St. Michael's Hospital, University of Toronto, Toronto, the Department of Medical Physics, Ontario Cancer Foundalion, and MoMaster University, Hamilton

Reprint requests to: Paul J. Muller, M.D., Division of Neurosurgery, Department of Surgery, St. Michael's Hospital, 38 Shuter Street, Toronto, Onario, Canada M5B 1A6 
Experience in the use of PDT in the treatment of brain tumours is growing. A number of clinical studies and their updates have been reported. ${ }^{12-21}$ We are reporting our first 50 patients with malignant supratentorial tumours treated with intra-operative PDT.

\section{Material and Methods}

\section{Patient Population}

Forty-five patients with primary malignant supratentorial brain tumours and 5 patients with solitary metastatic brain tumours were selected for PDT after obtaining informed consent and according to a protocol approved by the Ethics Review Committee of the University of Toronto and St. Michael's Hospital, Toronto. Patient characteristics and light dose characteristics are given in Table 1.

There were 22 patients with glioblastoma multiforme (GBM), 18 with malignant astrocytomas and, 2 with malignant ependymoma, and 1 each with primitive neuroectodermal tumour, malignant mixed glioma and malignant meningioma. For the purpose of assessment the patients with GBM and PNET were grouped together as GBM and the other primary tumours were grouped under the heading of non-GBM malignant glioma. There were 29 males and 21 females. The ages ranged from 17 to 73 (mean age $=48$ years). The pre-operative Karnofsky scores of the entire group ranged from 40-100 (mean $=73$ ).

In 28 of the 45 patients with primary tumours, the tumour had recurred after surgical treatment and radiotherapy; PDT was utilized in these patients as a component of their surgical palliation; in 17 patients PDT was used as a part of their primary treatment and radiotherapy was administered 1-3 weeks after PDT. All 5 cases of metastatic cerebral tumours had recurred after radiation therapy. The radiation dose, whether the radiotherapy was pre- or post-PDT, was 5000-5500 cGy administered in 5-6 weeks in all cases except one who received superfractionated radiation (6140 cGy) one year prior to recurrence and PDT.

\section{Photosensitizer}

The first 8 patients in this series received HPD (Photofrin I), procured from Photophrin Inc., Cheecktawaga, New York. The next 24 received DHE (Photofrin II), provided by Photofrin Medical Inc., Rariton, New Jersey. The remaining 18 cases in this series received either HPD kindly supplied by Dr. J. Kennedy, Ontario Cancer Foundation, Kingston, Ontario or DHE supplied by QLT Phototherapeutics Inc., Vancouver, British Columbia. The photosensitizers were administered over ten minutes through an intravenous line which was infusing $5 \%$ dextrose in saline. In the first 8 cases the dose approximated

\begin{tabular}{|c|c|c|c|c|}
\hline & All & GBM & Non-GBM & MET \\
\hline Number & 50 & 23 & 22 & 5 \\
\hline Mean Age & $48(17-73)$ & 48 & 45 & 61 \\
\hline \multicolumn{5}{|l|}{ Mean } \\
\hline Kamofsky & $73(40-100)$ & 71 & 75 & 70 \\
\hline Male/Fermale & $29 / 21$ & $13 / 10$ & $13 / 9$ & $3 / 2$ \\
\hline New/Recurrent & $33 / 17$ & $9 / 14$ & $8 / 14$ & $0 / 5$ \\
\hline Median Energy & 1440 & 1080 & 1650 & $2025(\mathrm{~J})$ \\
\hline \multicolumn{5}{|l|}{ Median Energy } \\
\hline Density & 27 & 24 & 37 & $61\left(\mathrm{~J} / \mathrm{CM}^{2}\right)$ \\
\hline
\end{tabular}

$5 \mathrm{mg} / \mathrm{kg}$; in all subsequent cases the dose approximated $2 \mathrm{mg} / \mathrm{kg}$. The photosensitizer was administered to each patient 18-24 hours prior to intra-operative photoillumination. After the administration of photosensitizer patients were kept in a subdued light environment for 7 days and advised to avoid direct and indirect sunlight for 60 days.

\section{Surgical Treatment and Photoillumination}

Eighteen to twenty-four hours after administration of photosensitizer the patients were taken to the operating room where a maximal tumour resection was carried out or a cyst drainage procedure was fashioned. The resulting tumour cavity was photoilluminated using an inflatable balloon applicator coupled to a 7.5 Watt argon dye pump laser (Cooper Medical, Mountain View, California).

The balloon applicator (Figure 1) has been described in detail elsewhere by Wilson et al. ${ }^{22}$ In brief, it consists of a metal cylinder through which 3 channels pass, a central channel and two side channels. The central channel was used to conduct a single strand optic fiber $(400 \mu \mathrm{m}$ core diameter, $800 \mu \mathrm{m}$ outside diameter, 0.4 nominal numerical aperture) which was coupled to the laser. The end of the fiber was cleaved so that light emerged as a forward directed cone in air. In order to convert this light cone into a uniform spherical distribution the fiber was passed through the cylinder into an inflatable balloon. The balloon was inflated via one of the side channels with a 1:1000 dilution of sterile Nutralipid or Intralipid (Pharmacia (Canada) Inc., Dorva], Quebec) which have been shown to be ideal light dispersion media. ${ }^{22}$ The degree of balloon inflation was such as to produce a snug fit in the tumour cavity (Figure 2).

The use of the applicator allowed in vivo measurement of the penetration depth of $630 \mathrm{~nm}$ light in the human brain in selected cases. The methods have been described elsewhere. 22,23

\section{Light Dose}

For each case the laser was tuned to a wavelength of $630 \mathrm{~nm}$; the wavelength was confirmed with a spectroscope (26-6270 Hartridge reversion spectroscope). The fiber output was measured with a radiometer/photometer (Photodyne model 88XLA, model 350 sensor head). Power at the fiber tip ranged from 0.175 to 1.000 Watts. The total light energy delivered ranged from 440 to 3888 Joules and the light energy density, measured at the applicator surface, ranged from 8 to $175 \mathrm{~J} / \mathrm{cm}^{2}$. No tissue heating occurred at these energy levels. In the 8 patients who had line fiber interstial photoillumination, in addition to cavitary illumination, the light energy delivered by the line fibers was $114-675$ Joules and the light dose was $60-945 \mathrm{~J} / \mathrm{cm}$.

\section{Post-Operative Management}

All patients received their post-operative. treatment in our neurosurgical ICU for a minimum of 72 hours. All PDT patients received dexamethasone $8 \mathrm{mg} q 6 \mathrm{~h}$ for 3-5 post-operative days with subsequent dose reduction; and phenytoin $100 \mathrm{mg} \mathrm{q} 8 \mathrm{~h}$. Patients were followed with regular neurological examinations and CT scans.

\section{Results}

\section{Complications of Photodynamic Therapy (whole series)}

There were two post-operative deaths; these occurred as the consequence of hematoma accumulation in extensive tumour 


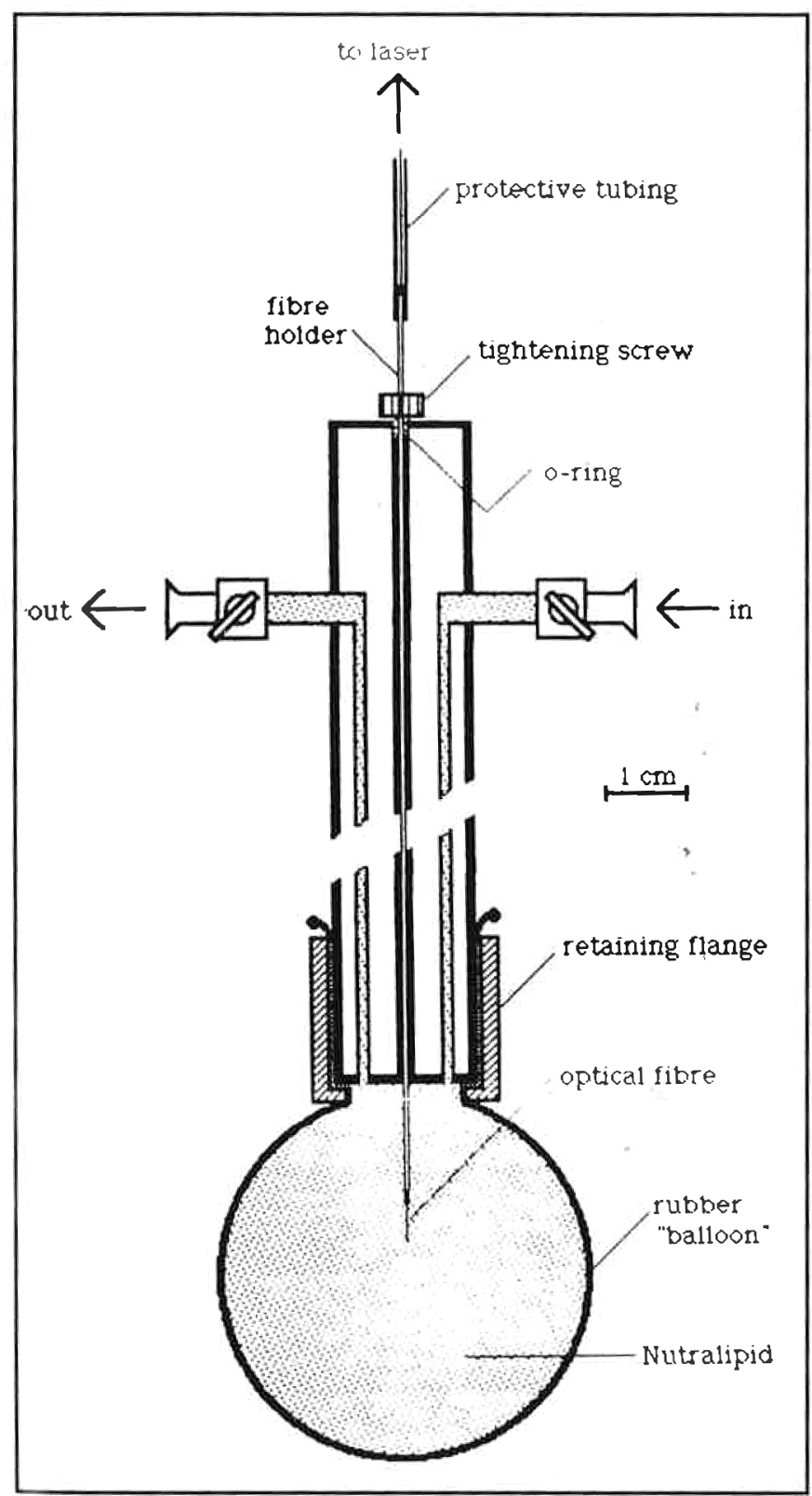

Figure 1-The balloon irradiator in schematic form.

resection cavilies. In 3 patients neurological function was worse post-operatively and did not recover. In these patients pre-operative hemiparesis was present and they underwent a radical subtotal resection of a large recurrent tumour mass. Although there was considerable post-operative cerebral edema further surgical treatment was not utilized. Five other patients had transient post-operative neurological worsening. In two of these cases acute reoperation was required for the treatment of intracranial hypertension secondary to cerebral edema. Brain and residual tumour tissue, resected at the second craniotomy, revealed hemorrhagic necrosis on histologic examination.

Four patients developed wound infections; two required sur. gical drainage and removal of an infected bone flap and two required only antibiotic therapy, since their infections were only superficial. Four patients, two of whom were hemiparetic,

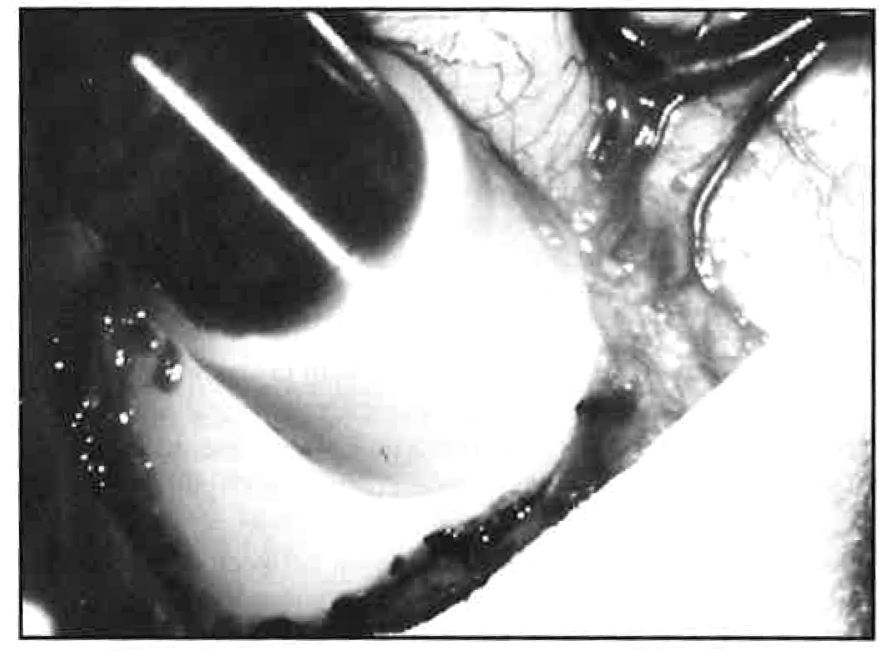

Figure 2 - The balloon irradiator in situ surrounded by brain.

developed deep vein thrombosis and required anticongulant therapy. One of these patients died of a pulmonary embolus while undergoing radiotherapy.

There were no adverse systemic reactions to the administration of the porphyrin photosensitizers. Two patients showed mild erythema after sun exposure. One patient who had an interstitial injection of DHE at his IV site developed a local second degree bum after exposure to low intensity room lights 8 days post-injection.

CT Tumour Response (malignant gliomas)

All patients showed change on their post-operative CT scans which could be attributed to surgery and/or PDT. However, in 12 of the 45 primary tumour patients, the tumour disappeared on CT scan. Of this group 6 did not receive any post-PDT radiotherapy or chemotherapy and had declining or no steroid requirement. In another 4 patients the area of original tumour remained stable or decreased; in spite of which tumour developed remote from the site of treatment. We concluded that the PDT associated response rate was $35 \%$.

In those cases where the tumour response was obvious the tumour tended to be cystic or small. Large solid tumours where the photoillumination could be surmised to be incomplete tended to show an incomplete CT scan response.

\section{Post-Operative Survival (malignant gliomas)}

In the interval berween PDT and death or last follow up there was a death rate of 0.92 per observation year. in the interval between first operation and death or last follow up there was a death rate of 0.41 per observation year. The death rates for the three pathologic tumour groupings are shown in Table 2. The calculated median survival, 1-year and 2-year actuarial survival rates, and deaths per observation year are shown in Table 3 by groupings. Patients with non-GBM primary gliomas, a higher Karnofsky score and younger age survived longer than their counterparts.

Patients with de novo tumours underwent post-PDT radiation; they had an insignificantly greater median survival after PDT than did the recurrent group whose members received no post-PDT radiation therapy. They showed similar survival at 2 years. 


\begin{tabular}{lccc}
\hline \multicolumn{4}{l}{ Table 2: Deaths Per Observation Year By Pathologic Grouping } \\
\hline \hline & Number & From PDT & From 1st Treatment \\
\hline Series & 50 & 1.00 & 0.41 \\
Non-GBM & 23 & 0.65 & 0.28 \\
GBM & 22 & 1.42 & 0.59 \\
MET & 5 & 2.27 & - \\
\hline
\end{tabular}

The median light dose for patients with primary gliomas was $1400 \mathrm{~J}$. There was no difference in median survival between the group whose members received $>1400 \mathrm{~J}$ and the group whose members received $<1400 \mathrm{~J}$; however, the high light dose group had a higher proportion of 1 and 2 year survivors. On the other hand there was a significant difference between high and low light doses in the non-GBM group. Those that received $>1500 \mathrm{~J}$ had a median survival almost three times that of the group whose members received $<1500 \mathrm{~J}$.

The 12 patients with primary malignant brain tumours treated with PDT who had a complete CT scan response had a median survival of 17.1 months with the 1 and 2 year survival of 62 and $38 \%$, respectively. The median survival of non total CT responders was 6.5 months with the 1 and 2 year actuarial survival of 22 and $11 \%$, respectively. It is evident that complete CT scan response is translated into prolongation of survival.

\section{DISCUSSION}

Tumours of the nervous system account for $0.45 \%$ of all deaths and approximately $3 \%$ of all cancer deaths in the United States. ${ }^{24}$ Primary brain tumours account for $2-3 \%$ of the cancer burden in North America. ${ }^{25}$ They are the 6th most common cause of cancer mortality in the population over the age of 20 years. ${ }^{25}$ Malignant tumours of the astrocytic type (glioblastoma multiforme and malignant astrocytoma) are the most common primary brain tumours. These tumours have a very bad progno-

\begin{tabular}{lccccc}
\hline \multicolumn{7}{c}{ Table 3: Survival of Patients with Primary Malignant Gliomas } \\
\hline \hline Subgroup & Number & Median & 1-Year & 2-Year & D/Year \\
\hline Glioma & 45 & 8.6 & 32 & 18 & 0.92 \\
GBM & 23 & 6.3 & 22 & 0 & 1.49 \\
Non-GBM & 22 & 10.9 & 43 & 31 & 0.88 \\
Age $<48$ & 23 & 8.1 & 31 & 22 & 0.82 \\
Age $>48$ & 22 & 7.0 & 34 & 14 & 1.05 \\
Karn $<75$ & 22 & 9.1 & 41 & 29 & 0.61 \\
Kam $>75$ & 23 & 6.5 & 24 & 7 & 1.37 \\
Newly Diagnosed & 28 & 9.9 & 38 & 21 & 0.72 \\
Recurrent & 17 & 6.6 & 28 & 16 & 1.33 \\
TJ <1400 & 22 & 7.5 & 23 & 9 & 1.15 \\
TJ $>1400$ & 23 & 7.7 & 42 & 26 & 0.70 \\
Non-GBM & & & & & \\
$\quad$ TJ <1650 & 11 & 6.6 & 27 & 27 & 0.76 \\
Non-GBM & & & & & \\
$\quad$ TJ $>1650$ & 11 & 18.0 & 59 & 36 & 0.42 \\
CT Complete & & & & & \\
RESP & 12 & 17.1 & 62 & 38. & 0.45 \\
CT Incomplete & 33 & 6.5 & 22 & 11 & 1.55 \\
\hline
\end{tabular}

$\mathrm{D} / \mathrm{YR}=$ deaths per observation year KARN $=$ Kamofsky score

$\mathrm{TJ}=$ total light energy administered sis; median survival after surgical treatment and post-operative radiotherapy is less than 1 year and the 2 year actuarial survival is less than $20 \% .^{26-30}$

Primary malignant brain tumours result in morbidity and mortality as the consequence of their local effects on the brain (they do not metastasize); therefore, improved local control would be expected to result in prolongation of survival. Photodynamic therapy (PDT), which consists of the exposure of neoplastic tissue to visible light of an appropriate wavelength in order to activate a photosensitizer administered prior to the light application, appears to be a local therapy worthy of assessment in the treatment of these highly lethal primary brain tumours.

Experience in the use of PDT in the treatment of brain tumours is limited. Perria et al ${ }^{20}$ were the first to use PDT in the treatment of malignant brain tumours; they reported no significant complications attributable to the PDT in their series of 9 patients. Laws et al $^{14}$ reported a phase I study utilizing PDT in the treatment of recurrent malignant brain tumours. No neurological complications occurred as the consequence of the photodynamic therapy. McCulloch et al ${ }^{17}$ reported their experience with malignant astrocytic tumours treated with PDT and postoperative radiotherapy; 3 of the 9 patients were alive 17-42 months after treatment. Their complication rate was small although they did note an increase in post-operative cerebral edema. Laws and Wharen ${ }^{15}$ noted that 3 patients developed wound infections and 2 had transient cerebral edema among 22 brain tumour patients which they had treated with PDT. Laws et al ${ }^{16}$ subsequently noted that if tissue heating is avoided during PDT post therapy cerebral edema does not occur. Muller and Wilson ${ }^{20}$ reported their preliminary experience in 8 patients using intraoperative cavitary photoillumination by an inflatable balloon with non post-operative mortality. Kaye et al ${ }^{12}$ reported the results in 23 patients with brain tumours which suggested that higher doses of light resulted in longer survival than lower doses. They did not identify any increase in cerebral edema and noted no significant toxicity. Kostron et al ${ }^{13}$ treated a number of brain tumour patients with intra-operative local HPD application prior to light administration. Perria et $a^{21}$ reported 8 further cases and elucidated the short comings of PDT in the treatment of brain tumours.

We have noted an increase in cerebral edema and a significant increase in post-operative ICP in spite of the administration of peri-operative steroid. The mean post-operative ICP over the first 24-36 hours was twice that of a control group whicl underwent similar surgery for similar pathology but did not receive intra-operative PDT. 19 In two patients who deterioralcd postoperatively secondary to cerebral edema, reoperation yielded gross hemorrhagic necrosis of residual tumour. In our method of photoillumination using the balloon applicator no increase in local tissue temperature occurs.

We suspected that the cerebral edema was the consequence of tissue necrosis early after the application of PDT. The elabo: ration of the products of tissue necrosis result in local and dis: tant edema as these products diffuse through the neuropil. There appeared to be a relationship between the size of the resection cavity (and thus the area photoilluminated) and the degree of cerebral edema. The larger the surface area photoilluminated the greater the tissue volume subjected to the photodynanic effect and the larger the expected tissue necrosis. The use of the balz loon itradiator itself may have contributed to the cerebral edent? 
by acting as a brain retractor; we did attempt to minimize this pressure effect by careful placement of the balloon.

In our series 17 patients were newly diagnosed and thus had radiation therapy after $\mathrm{PDT}$. We identified no increase in radiation related complications post-PDT. In the series of Kaye et al 12 palients were newly diagnosed and underwent postPDT radiation with no radiation associated complications.

Laws and Wharen ${ }^{15}$ noted a $9 \%$ infection rate in their series. We have had a $8 \%$ rate although only 2 patients required surgical treatment for their infections. This infection rate is approximately 4 times the expected. It is likely related to the increased operative time for pholoillumination, the increased intra-operative equipment requirements and the often compromised tissues (in our series all wound and bone flap infections occurred in patients who had previous surgery and radiotherapy).

We measured the penetration depth (that distance in $\mathrm{mm}$ through which the light flux is reduced to $37 \%$ of its incident intensity) of $630 \mathrm{~nm}$ light in brain in vivo in 8 patients. 23 There was considerable variation in the penetration depth from patient to patient and from place to place in the same patient. Nevertheless, the average penetration depth was greater in tumour than in nomal brain. The mean ( $\mathrm{mm}$ ) and s.d. for the penetration depth of brain, tumour infiltrated brain and tumour alone were $1.5 \pm 0.43,2.4 \pm 1.2$ and $2.9 \pm 1.5$, respectively. The range of penetration depths for brain, tumour infiltrated brain and tumour alone were $1.2-2.2,0.8-4.9$ and $1.2-4.5 \mathrm{~mm}$, respectjvely. Although the "tumour necrosis distance" may be 3-5 times the penetration depth, this distance is relatively short in comparison to the usual size of malignant glial neoplasms which present with an average mass of greater than 30 grams. The relatively shor tissue penetration of light limits the degree of tumour tissue photoillumination and may account for some of our failures.

In our series 45 patients had primary malignant supratentorial neoplasms and 5 had single cerebral metastases. The method of surgical treatment was similar in all cases although there was variation in light dose. The observed death rates for single cerebral metastases, GBM or non-GBM primary gliomas were 2.27, I.42 and 0.65 deaths per observation year, respectively. Table I summaries the survival results. In patients with non-GBM malignant gliomas the group that received greater than the median light energy survived longer than those who received less than the median. And, those who had a full posi-PDT CT scan response survived significantly longer than those whose CT response was incomplete.

Because of the lack of prospective controls a conclusion pertaining to the efficacy of PDT in the treatment of malignant brain tumours can not yet be made. However, a number of conclusions can be drawn.

PDT had an acceptable level of risk in the treatment of patients with maligrant brain tumours. PDT was active against some gliomas. CT scan response translated into prolonged survival. Higher light doses appear to improve survival. The relatively short penetration depth was a limiting factor.

\section{ACKNOWLEDGEMENT}

This work was supported by the National Cancer Institute of Canada.

\section{REFERENCES}

1. Walker MD. Brain tumour study group: a survey of current activities. Natl Cancer Inst Monogr 1977; 46: 209-212.

2. Lipson RL, Baldes EJ, Olsen AM. The use of a derivative of henatoporphyrin in tumots detection. JNCL 1961; 26: 1-11.

3. Dougherty TJ, Wieshaupt KR, Boyle DG. Photosensitizers, Im:

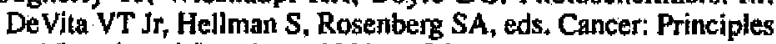
and Practice of Oncology. 1982; 1836-1844.

4. Kaye AH, Morstyn G, Appuzzo LJ. Photoradiation therapy and its polential in the management of neurological tumours. J Neurosurg 1988; 69: 1-14.

5. Kaye AH, Morstyn G, Ashcroft RG. Uptake and retension of hematoporphyrin derivative in an in vivo/in vifro model of cerebral glioma. Neurosurgery 1985; 17: 883-890.

6. Little FM, Gomer CJ, Hyman S, et al. Observations in studies of quantitative kinetics of tritium labelled hematoporphyrin derivatives (HPDI and HPDID in the nomal and neoplastic rat brain model. J Neurooncol 1984; 2: 361-370.

7. Wharen RE Jr, Anderson RE, Laws ER Jr. Quantitation of hematoporphyrin derivative in human gliomas, experimental nervous system tumours, and normal tissues. Neurosufgery 1983; 12: 446-450.

8. Boggan JE, Walter R, Edwards MS, et al. Distribution of hematoporphyrin derivative in the rat $9 \mathrm{~L}$ gliosarcoma brain tumour analyzed by digital video fluorescence microscopy. J Neurosutg 1984: 61: 1113-1119.

9. Granelli SG, Diamond I, McDonagh AF, et al. Photochemotherapy of gtioma cells by visible light and hematoporphyrin. Cancer Res 1975; 35: 2556-2570.

10. Kaye AH, Morstyn G. Photoradiation therapy causing selective lumour kill in a rat glioma model. Neurosurgery 1987; 20: 408415.

11. Cohen AM, Wood WC, Bamberg M, et al. Cytotoxicity of human brain tumours by hematoporphyrin derivative. J Surg Res 1986; $41:: 81-83$.

12. Kaye AH, Morsyn G, Brownbill D. Adjuvant high dose photoradiation therapy for the treatment malignant gliomas a phase I-2 study. J Neurosurg 1987:67: $500-505$.

13. Kostron $H$, Weiser $G$, Fritsch $W$, et al. Photodynamic therapy of malignant brain tumours: clinical and neuropathological results. Photochem Photobiol 1987; 46: 937-943.

14. Laws ER, Cortese DA, Kinsey JH, et al. Photoradiation therapy in the treatment of malignant brain tumours: a feasibility study. Neurosurg 1981; 9: 672-678.

15. Laws ER, Wharen RE Jr. Comments. Neurosurgery 1984; 15: 807809.

16. Law ER, Wharen RE Jr, Anderson Re. Photodynamic therapy of brain qumours. In: Jori $\mathrm{G}$, Perria $\mathrm{C}$, eds. Photodynamic Therapy of Tumours and Other Diseases. Libreria Progetto Editore. Padova, 1985.

17. McCulloch GAJ, Forbes IJ, Lee See K, et al. Phototherapy in malignant brain tumours. In: Doiron DR, Gomer CJ, eds. Porphyrin Localizarion and Treatment of Tumours. New York: AR Liss Inc, 1984; 709-718.

18. Muller PJ. Wilson B. Photodynamic therapy (PDT): cavitary photoiflumination of malignant cerebral tumours using a laser coupled inflatable balloon; a preliminary repott. Can 3 Neurol Sci 1985; 12: 371.373 .

19. Muller PJ, Wilson BC. Photodynamic therapy of malignant primary brain tumours: clinical effects, post-operative intracranial ICP, and light penetration of brain. Photochem Photobiol 1987; 46: 929-936.

20. Perria C, Capuzzo T, Cavagnaro G, et al. First attempts at the photodynamic therapy of human gliomas. J Neurosurg Sci 1980; 24: $119-129$.

21. Perria C. Carai M, Falzoi A, et al. Photodynamie therapy of malignant tumours: clinical results of, difficulties with, and future prospects for the neurosurgical applications. Neurosurg 1988; 23: $557-563$

22. Wilson B, Muller PJ, Yanche JC. Insirumentarion and light dosimeiry for intra-operative pholodynamic therapy (PDT) of malignant brain tumours. Phys Med Biol 1986; 32: 125-133. 
23. Muller PJ, Wilson BC. An update on the penetration depth of $630 \mathrm{~nm}$ light in normal and malignant human brain tissue in vivo. Phys Med Biol 1986; 31: 1295-1297.

24. U.S. Department of Health Education and Welfare - Public Health Service Vital Statistics of the United States 1966, vol II; Vital Statistics Rates in the United States 1940-1960. Washington D.C., 1968.

25. Cutler SJ, Young JL. Third national cancer survey. Incidence data Natl Cancer Inst Monogr 1975; 411-454.

26. Gutin PH, Wara WM, Phillips TL, et al. Hypoxic cell radiosensitizers in the treatment of malignant brain tumours. Neurosurg 1980; 6: 567-576.

27. Payne J, Simpson J, Keen C, et al. Malignant astrocytoma: hyperfractionated and standard radiotherapy with chemotherapy in a randomized prospective clinical trial. Cancer 1982; 50: 23012306.

28. Shin KH, Muller PJ, Geggie PHS. Superfractionation radiation therapy in the treatment of malignant astrocytoma. Cancer 1983; 52: 2040-2043.

29. Shin KH, Urtasun RC, Thomas $\mathrm{H}$, et al. Multiple daily fractionated radiation therapy and misonidazole in the management of malignant astrocytoma. Cancer 1985; 56: 758-60.

30. Walker MD, Green SB, Byar DP, et al. Randomized comparisons of radiotherapy and nitrosoureas for the treatment of malignant glioma after surgery. N Engl J Med 1980; 303: 1324-1329. 